\title{
Effectiveness of a Nursing Educational Program on the Outcomes of Pregnancy During Breastfeeding at Assiut City
}

\author{
Hamida Alm El Dien Abd El-Hafez \& Neama Mohamed El-Magrabi, \\ Lecturer of Obstetrics \& Gynecological Nursing Health Nursing, Faculty of Nursing Assiut University, \\ Assistant Professor of Community Health Nursing , Faculty of Nursing, Assiut University.
}

\begin{abstract}
Lactation-pregnancy overlap is defined as the continuation of breastfeeding into the first, second, or even third trimester of pregnancy. Pregnancy during breastfeeding is common in Egypt and is often unintended. Overlap is probably common because many women may not realize they are pregnant for several months after conception. The aim of the present study is to evaluate the effect of an educational program on the outcome of pregnancy during breastfeeding at Assiut City .Designs a quasi-experimental, prospective- cohort study was used. Setting: the study was conducted in a six Maternal and Child Health Centers in West and East Assiut city. Subjects: All lactation women who attended the selected antenatal care centers during the period of data collection were evaluated for eligibility $(n=240)$. The tools: used for data collection consisted of structured interviewing questionnaire (pre-posttest) and follow-up to collect personal, obstetric data, knowledge about balanced meal and calcium intake during pregnancy, consumption of milk products, times/ week symptoms of low calcium intake and information about the effect of breastfeeding- pregnancy overlaps on pregnancy outcome on labor and newborn and Information about the effect of breastfeeding-pregnancy overlaps on pregnancy outcome. Results showed that the majority of the pregnancies were unintended for both groups. Also, statistical significant decrease among the study group than that of the control groups regarding complications as miscarriage, vaginal bleeding during pregnancy, placental separation, delayed fetal growth, elevation of blood sugar, eclampsia and anemia. Likewise, complication of delivery, and indication for cesarean section, were better among the study group than that of the control group. Also, more than one third of newborns' of the study group of mothers were referred to Premature Care Unit compared to nearly half of the control group. Conclusion: pregnant lactating women who attended the educational program had better pregnancy/ delivery outcomes, also, their newborns. Recommendation: Continuous postnatal counseling and health education classes about nutritional needs focusing on pregnancy to prevent complication for mother and children during breast feeding and weaning practices.
\end{abstract}

\section{Keywords: Overlap Pregnancy During Breastfeeding, Pregnancy, Complications \& Newborn.}

\section{Introduction}

Lactation-pregnancy overlap is defined as the continuation of breastfeeding into the first, second, or even third trimester of pregnancy. Several studies have shown that this practice is widespread in many countries around the world (Conde- Agudelo et al., 2012). Pregnancy during breastfeeding is common in Egypt and is often unintended. Overlap is probably common because many women may not realize they are pregnant for several months after conception (Shaaban \& Glasier, 2008). It has been reported that $86 \%$ of unintended postpartum pregnancies occurred before contraceptive usage and $88 \%$ of them resulted in induced abortion.

Since suckling during breastfeeding induce release of oxytocin from the posterior pituitary gland, it stimulates uterine contraction and facilitates postpartum uterine involution. Therefore, it is possible that breast-feeding during pregnancy can lead to impaired utero-placental blood flow, fetal growth retardation, miscarriage, preterm labor, premature labor, low birth weight and intrauterine death (Madarshahian et al., (2012) and Albadran, 2013).

Birth spacing is an important element of making pregnancy safer, so the WHO recommends a minimum birth-to-pregnancy interval of 2 years to reduce the incidence of maternal and fetal risks in each pregnancy. This recommendation is consistent with the recommendation of UNICEF that recommends women to breastfeed each child for at least 2 years for the benefit of its nutritional status, growth and development, and general health (Goma, 2011).

The emphasis on achieving and maintaining a nutritionally adequate diet is important, and a poor maternal diet should be improved during pregnancy and breastfeeding to maintain the mother's health. The relevance of maternal nutrition to pregnancy begins before woman's conceives. Maternal iron status pre-pregnancy is especially important because 
women need to go into pregnancy with adequate body stores. Once pregnancy is confirmed, it is a good time for health practitioners and maternity care givers to emphasis the importance of good nutrition to the pregnant woman, maternal stores are particularly important if the woman is planning another pregnancy (Ministry of Health, 2006).

Health education programs are primary level of prevention that aims to prevent the occurrence of any health problem. They help in reducing the morbidity and subsequent suffering. Health education helps in bringing change in health behaviors which promote and protect health (CDC, 2007). It is a continuous process based upon developed criteria and concerned with measurement of the performance of the learners, the effectiveness of the teacher and the quality of the program (Brothers, 2009).

Community health nurse and Midwife should educate women during pregnancy and lactation about the benefits of breast feeding as a natural method of delaying pregnancy if exclusive breastfeeding done. They need to educate mothers to maintain exclusive breast feeding for the first 6 months. Mother's difficulties with breast feeding should be identified early, and followed frequently with assistance in breast feeding (Huang et al., 2012).

In the immediate puerperium and during the first days after birth, practical support is one of the most important skills in breast-feeding counseling. To achieve this, knowledge is required about what mothers know about breast feeding. Education of women to prevent early supplementary feeding of babies, and how to support exclusive breast feeding could improve infant health and delay pregnancy. Nurses are in a key position to carry out the role of an educator, because they are the health care provide who have continuous contact with women, and is usually most accessible source of information for women (Houghton, 2009).

Significance of the study

Pregnancy during breastfeeding (PDBF) may result in unplanned or mistimed, and sometimes unwanted childbirth. While prolonged breastfeeding is common in rural Egypt, pregnancy during breastfeeding occurs in more than 1 in 4 women, and nearly 1 in 3 of these pregnancies is unplanned. Women breastfeeding for longer than 6 months postpartum should initiate other modern methods of contraception to avoid unplanned pregnancy irrespective of breastfeeding style or menstrual status (Shaaban, 2008). Although breastfeeding during pregnancy is a common practice in many cultures, most of mothers who have become pregnant while breastfeeding have concerns of safety, nutritional needs and comfort (Ismail et al., 2009).
The Demographic and Health Survey (DHS) data consider an inter-birth interval of less than 24 months short; have increased risk of adverse prenatal outcomes. These outcomes include, abortion, preterm birth (less than 37-week of gestation), low birth weight (less than $2500 \mathrm{gm}$ at birth), intrauterine growth retardation (IUGR) and fetal death (Sengul et al., 2012). Shorter birth intervals increase the likelihood of a pregnancy-lactation overlap. It has been suggested that an overlap could produce suboptimal outcomes for both pregnancy and subsequent lactation(Smith et al., 2003).

\section{Aim of the Study}

The aim of the present study is to evaluate the effect of an educational program on the outcome of pregnancy during breastfeeding through assess knowledge and practices of pregnant women during breastfeeding regarding nutrition, developed and implement an intervention program about nutrition for pregnant women during breastfeeding.

\section{Research Hypothesis}

- Pregnant-lactating women who will receive the educational program will improve outcomes of lactating women health and their newborn.

- Infants of Pregnant -lactating women who will receive the educational program will improve outcomes than those in the control group.

\section{Subjects and Methodes}

\section{Research Design}

A quasi experimental, prospective study was used to fulfill the aim of the study.

\section{Setting of study}

The study was conducted in six Maternal and Child Health Centers in West and East Assiut city namely Colta, Ktharb, Elarbaeen, Hay Shark Kaydwany, Phruail and El Waldey. These centers provide free services to women. These centers open for women and children from 8 am to $1 \mathrm{pm}$.

\section{Subjects}

All pregnant women attended the selected randomly antenatal care centers during the period of data collection were evaluated for eligibility. The total numbers of eligible women who volunteered to participate and fulfill the required criteria and continued to the end of the study were 240 women. Fifteen women were recruited for the pilot study and were given the regular care and excluded from the total sample. The remaining 240 women were randomly divided into two equal groups, (study and control), 120 woman in each group.

Inclusion criteria

- All multiparous pregnant women presented to the 
$\mathrm{MCH}$ centers in the first trimester of pregnancy (less than 12 weeks pregnant) that got pregnant during breastfeeding who are:

- Without medical complication as diabetes mellitus, hypertension....etc

- Willing to participate in the study.

Tools of the study

The tools used for data collection consisted of structured interviewing questionnaire used (preposttest) and follow-up.

Tool (1): The structured interview questionnaire consisted of the three following parts:

Part I: Personal data included: age, address, telephone number, level of education, occupation.

Part II: Obstetrical and breastfeeding history included: number of previous deliveries, number of miscarriages, number of previous breastfed children, duration of breastfeeding during pregnancy, the longest breastfeeding periods in previous children, time between weaning last child (if weaned the baby) and beginning of current pregnancy, duration of lactation after the last delivery, and the effect of pregnancy on quantity of milk.

Part III: Knowledge about balanced meal and calcium intake during pregnancy: Woman was asked about consuming milk products, times/ week she consumed milk products, type of dairy product she consumed and any symptoms of low calcium intake (Problem in teeth (drop or decay), Vertigo or palpitation.... Etc

Tool (2): Information from medical records consisted of the following two parts:

Part I: Information about the effect of breastfeeding-pregnancy overlaps on pregnancy outcome. Every woman in both groups was followed during her visit to the centers until delivery to know if there was any complication during current pregnancy (miscarriage, vaginal bleeding during pregnancy, placental separation (partially or completely), and delayed fetal growth, elevation of blood sugar, elevation of blood pressure, eclampsia and anemia.

Part II: Follow up sheets contained the following two sheets

Sheet (A): -Every woman in both groups was followed up during delivery to collect data about the mode of delivery, the time of labor, problems or complications during labor (Ante-partum or Postpartum hemorrhage, premature rupture of membranes and prolonged labor, Ante-partum hemorrhage)and indication of cesarean section (if any)

Sheet (B): -Also, infants were followed immediately after delivery for any abnormality as macrocosmic baby, abnormal position of fetus, and newborn's weight at the time of delivery, if the baby was referred to PCU and reason for referral (small for gestational age, low birth weight >2500 gm ....etc.

* Validity: The tools were reviewed for validity by 3 experts in Community Health Nursing and Obstetrics and Gynecology.

* Reliability: The tools were measured for reliability using Cronbach Alpha (.87)

Ethical considerations

The investigator explained the nature and the aims of the study then an oral consent of women was obtained. Women were reassured that any obtained information will be used only for the purpose of the study. A code number will be used for every woman to maintain confidentiality. The study maneuvers had no actual or potential harm on women and professional help will be provided whenever needed. Also, there was no risk for participation in the study as no drug use or clinical procedure will be involved. Any participant in the study has the right to refuse answering any of the questions or to stop the interview at any time. She also had the right to withdraw from the study at any. Woman's participation in the study had no positive or negative effect on the service she will receive.

\section{Pilot study}

A Pilot study was conducted on 15 women during the first two weeks to test the clarity, applicability of the questions and time needed for each interview. According to the results of the pilot study the necessary modifications were done.

\section{Field work}

The study passed through 4 phases: Each participant was assigned to the proper group according to the study profile. A code number was used for every woman to maintain confidentiality. The researcher presented the questionnaire to the women who can read and write, and filled the questionnaire for the illiterate women (pre- posttest) .Each interview took about 15-20 minutes.

Phase (1)

Preparatory phase

The researcher reviewed related literature (local \& international), using text books, web articles and scientific magazines. The tools were then prepared.

-Before conducting the study an official approval was obtained from the Dean of Faculty of Nursing, Assiut University, to the Undersecretary of Ministry of Health and Population to get his approval to conduct the study in the selected health centers. The aim of the study was explained to each director of the health centers to gain his cooperation. At the first meeting with the women the investigators introduced 
themselves, and explained the nature and aims of the study then obtained participants' oral consent.

\section{Phase (2): Implementation of the educational program}

Women in the pilot study and control group received the routine care rendered by the $\mathrm{MCH}$ nurses. The women in the study group were given the educational program that includes:

The Nursing role with the study group, extended beyond health education, it included:

1. Carrying out professional act as assessing blood pressure, blood glucose, presence of edema, fetal heart sound and presence of any complication.

2 Guidance of women along the pregnancy till delivery and till the end of the follow up.

Health education about nutrition during pregnancy which included recommendations regarding rest, getting enough sleep, hygiene, weaning the current child in addition to the following :

- Eating enough calories for adequate weight gain, pregnant or breastfeeding women needs to eat 300 more calories than usual pregnant woman, to provide the extra energy, Three hundred calories equals to a small snack, such as a sandwich of honey and butter and a glass of milk should be added,

- Small frequent meals 3-5 meals and snacks per day,

- Choose foods with a lot of fiber-fruits, vegetables, dry beans, whole grain breads and cereals, and other whole grain products to avoid constipation,

- Eight or more cups of water each day,

- Low salt intake to reduce elevation in blood pressure,

- Folate (or folic acid) is needed for the growth and development of the baby. It is especially important in the first trimester of pregnancy. A good intake of folate reduces the risks of the baby being born with some abnormalities such as spine bifida. Dietary sources high in folate include green vegetables such as broccoli, spinach and green leafy vegetables, some fruits and fortified cereals

- Iron is needed to form the red blood cells for the mother and the baby, It helps carry oxygen in the blood and is needed for the baby to grow, the sources of iron are lean meats (especially red meat) some vegetables (especially green leafy ones), legumes, and fortified cereals;

- Limit the intake of tea or coffee with meals help the body get iron from the food or drink. Include vitamin $\mathrm{C}$ with meals (e.g. citrus foods, tomato, and capsicum) to absorb iron better.
- Calcium is another important nutrient throughout pregnancy about $1,000-1,200 \mathrm{mg}$ is needed per day, equivalent to about 3-4 glasses of milk per day. Food sources e.g., dairy products, fortified foods/juices, cooked spinach and broccoli are good sources of Calcium.

- Protein is especially important during the second trimester, to help in the development and growth of the fetus's vital organs.

- The second trimester may also be a good time to begin focusing on omega-3 fatty acid intake, either from foods (such as salmon or other fatty fishes) (Ministry of Health, 2006).

- Weaning the child: Nutritional needs of children, reason for weaning, timing...

- Family planning: Types, time, barriers

Phase (3): Follow- up phase

Every woman in both groups was followed either in the center or during home visit until delivery, to complete the required data and evaluate the efficacy of the educational intervention. At the end the first interview, the researcher gave the participants a follow up card including patient serial number and basic information about each case and the follow up schedule. The follow up card included contact details of $\mathrm{MCH}$ center and the researcher. The follow up schedule was like the standard follow up schedule of $(\mathrm{MCH})$ center containing date of the women who participate in the study, and those with skeptical fetal problem were referred to ultrasound for detection of fetal complications and data was recorded.

Phase (4): Evaluation of the nursing educational program

-Each participant in the study group and control group was interviewed during or after labor for evaluating the effect of the nursing program on breastfeeding - pregnancy overlap on infant/ pregnancy outcome and to identify duration, type, problems or complications that might occur during pregnancy or labor for the mother and the baby.

-Also, the post test was done at the end of the final visit/ follow up; to compare the results of the preposttest and follow ups.

-In addition, the post test was completed for the women in the control group to be used in comparing pregnancy outcomes for both group and evaluate the effectiveness of the nursing educational program.

\section{Statistical design}

The collected data was coded, tabulated and analyzed using the statistical package for social science programs (SPSS) version 16. Continuous data was expressed as frequency, percentage, means and Standard deviation (SD). Discrete data was expressed as frequency and percentage. Comparison between variables was done using probability $(\mathrm{P}$ value) less than 0.05 was considered significant and 
less than 0.001 was considered highly significant.

\section{Results}

Table (1): Distribution of the demographic characteristics of the study and control groups

\begin{tabular}{|c|c|c|c|c|c|}
\hline \multirow{2}{*}{ Demographic characteristics } & \multicolumn{2}{|c|}{ Study group $(n=120)$} & \multicolumn{2}{|c|}{ Control group $(n=120)$} & \multirow{2}{*}{ P-value } \\
\hline & No. & $\%$ & No. & $\%$ & \\
\hline \multicolumn{5}{|l|}{ Age } & \multirow{5}{*}{0.871} \\
\hline$<25$ years & 39 & 23.5 & 31 & 25.8 & \\
\hline $25-$ & 42 & 35.00 & 39 & 32.5 & \\
\hline $30-$ & 18 & 15.00 & 27 & 22.5 & \\
\hline$\geq 35$ years & 21 & 17.5 & 23 & 19.2 & \\
\hline Mean \pm SD & \multicolumn{2}{|c|}{$28.82 \pm 4.22$} & \multicolumn{2}{|c|}{$3.95 \pm 29.33$} & 0.911 \\
\hline \multicolumn{5}{|l|}{ Husband occupation } & 0.07 \\
\hline Governmental Work & 54 & 45.5 & 62 & 51.7 & \\
\hline Private Work & 66 & 55.00 & 58 & 48.3 & \\
\hline \multicolumn{5}{|l|}{ Level of education } & 0.092 \\
\hline Illiterate or Read \& write & 36 & 30.0 & 39 & 32.5 & \\
\hline Basic education & 42 & 35.00 & 44 & 36.7 & \\
\hline school secondary & 24 & 20.00 & 22 & 18.3 & \\
\hline University & 18 & 15.00 & 15 & 12.5 & \\
\hline \multicolumn{5}{|l|}{ Mothers occupation } & 0.143 \\
\hline Working & 38 & 31.7 & 36 & 30.00 & \\
\hline Not working & 82 & 68.2 & 84 & 70.00 & \\
\hline
\end{tabular}

Table (2): Distribution of the past obstetric history of the study and control groups.

\begin{tabular}{|c|c|c|c|c|c|}
\hline \multirow{2}{*}{ Items } & \multicolumn{2}{|c|}{ Study group $(n=120)$} & \multicolumn{2}{|c|}{ Control group $(n=120)$} & \multirow{2}{*}{ P-value } \\
\hline & No. & $\%$ & No. & $\%$ & \\
\hline \multicolumn{5}{|c|}{ Number of previous deliveries } & \multirow{3}{*}{$0.000 *$} \\
\hline One & 46 & 38.5 & 19 & 15.6 & \\
\hline$>1$ & 74 & 61.5 & 101 & 84.4 & \\
\hline Mean \pm SD & \multicolumn{2}{|c|}{$2.39 \pm 1.54$} & \multicolumn{2}{|c|}{$2.64 \pm 1.18$} & 0.036 \\
\hline \multicolumn{5}{|l|}{ Number of living children } & \multirow{5}{*}{$0.000 *$} \\
\hline One & 49 & 40.7 & 19 & 16.0 & \\
\hline Two & 32 & 26.3 & 45 & 37.0 & \\
\hline Three & 17 & 14.4 & 40 & 33.7 & \\
\hline Four of more & 22 & 18.5 & 16 & 13.3 & \\
\hline Mean \pm SD & \multicolumn{2}{|c|}{$2.26 \pm 1.44$} & \multicolumn{2}{|c|}{$2.49 \pm 1.02$} & 0.031 \\
\hline \multicolumn{5}{|c|}{ Number of previous miscarriages } & \multirow{3}{*}{0.020} \\
\hline None & 93 & 77.5 & 103 & 85.6 & \\
\hline One or more & 27 & 22.5 & 17 & 14.4 & \\
\hline Mean \pm SD & \multicolumn{2}{|c|}{$0.27 \pm 0.56$} & \multicolumn{2}{|c|}{$0.19 \pm 0.54$} & 0.100 \\
\hline \multicolumn{5}{|c|}{ Pregnancy during breastfeeding } & \multirow{5}{*}{0.143} \\
\hline Intended & 26 & 21.5 & 27 & 22.3 & \\
\hline Unintended & 94 & 78.5 & 93 & 77.7 & \\
\hline Used contraceptives & 35 & 29 & 36 & 30 & \\
\hline Not used contraceptives & 85 & 71 & 84 & 70 & \\
\hline
\end{tabular}


Table (3): Distribution of the breastfeeding history of the two groups

\begin{tabular}{|c|c|c|c|c|}
\hline \multirow{2}{*}{ Items } & \multicolumn{2}{|c|}{ Study group $(n=120)$} & \multicolumn{2}{|c|}{ Control group $(n=120)$} \\
\hline & No. & $\%$ & No. & $\%$ \\
\hline \multicolumn{5}{|c|}{ Number of previous breastfed children } \\
\hline One & 49 & 40.7 & 20 & 16.7 \\
\hline Two & 33 & 27.8 & 44 & 36.6 \\
\hline Three & 16 & 13.3 & 40 & 33.3 \\
\hline Four of more & 22 & 18.2 & 16 & 13.4 \\
\hline Mean \pm SD & \multicolumn{2}{|c|}{$2.21 \pm 1.38$} & \multicolumn{2}{|c|}{$2.46 \pm 1.03$} \\
\hline \multicolumn{5}{|c|}{ Longest breastfeeding periods in previous children } \\
\hline$<18$ months & 47 & 38.9 & 8 & 6.3 \\
\hline 18 - months & 46 & 38.1 & 59 & 49.3 \\
\hline$\geq 24$ months & 27 & 23.0 & 53 & 44.4 \\
\hline Mean \pm SD & \multicolumn{2}{|c|}{$17.76 \pm 5.24$} & \multicolumn{2}{|c|}{$21.22 \pm 3.16$} \\
\hline \multicolumn{5}{|c|}{ Mean age of youngest child at the time of recruitment in the study in months } \\
\hline Mean age \pm SD & \multicolumn{2}{|c|}{$13.02 \pm 4.60$} & \multicolumn{2}{|c|}{$14.04 \pm 4.55$} \\
\hline \multicolumn{5}{|c|}{ Duration of breastfeeding during the current pregnancy till delivery } \\
\hline$<1$ year & 64 & 53.3 & 5 & 3.3 \\
\hline $1-<2$ years & 52 & 43.7 & 86 & 71.9 \\
\hline$\geq 2$ years & 4 & 3.0 & 29 & 24.8 \\
\hline Mean \pm SD (months) & \multicolumn{2}{|c|}{$12.25 \pm 4.71$} & \multicolumn{2}{|c|}{$19.17 \pm 3.99$} \\
\hline
\end{tabular}

Table (4): Distribution of the comparison of the study group women's knowledge about component of balanced meal before / after the educational program.

\begin{tabular}{|c|c|c|c|c|c|}
\hline \multirow{3}{*}{ Items } & \multicolumn{4}{|c|}{ Study group $(n=120)$} & \multirow{3}{*}{ P-value } \\
\hline & \multicolumn{2}{|c|}{ Pre-intervention } & \multicolumn{2}{|c|}{ Post-intervention } & \\
\hline & No. & $\%$ & No. & $\%$ & \\
\hline \multicolumn{5}{|l|}{ Definition of balanced meal } & \multirow{2}{*}{0.0000} \\
\hline Correct & 45 & 37.50 & 115 & 95.83 & \\
\hline Incorrect & 75 & 62.50 & 5 & 4.17 & \multirow{6}{*}{0.000} \\
\hline \multicolumn{5}{|l|}{ Factors determined meal } & \\
\hline Age & 30 & 25.0 & 116 & 96.67 & \\
\hline Physiological status as (pregnancy and lactation) & 28 & 23.33 & 118 & 98.33 & \\
\hline Physical activity & 20 & 16.67 & 118 & 98.33 & \\
\hline Don't know & 22 & 18.33 & 2 & 1.67 & \\
\hline \multicolumn{5}{|l|}{ Essential components of balanced meal:\# } & \multirow{4}{*}{0.011} \\
\hline Carbohydrates & 60 & 50.00 & 119 & 99.17 & \\
\hline Protein & 55 & 45.83 & 119 & 99.17 & \\
\hline Fats & 46 & 38.33 & 118 & 98.33 & \\
\hline Vitamins & 42 & 35.00 & 117 & 97.50 & \\
\hline Minerals & 33 & 27.50 & 117 & 97.50 & \\
\hline Water & 35 & 29.17 & 119 & 99.17 & \\
\hline Don't know & 3 & 2.50 & 0.0 & 0.00 & \\
\hline \multicolumn{6}{|l|}{ Consume milk products } \\
\hline Daily & 50 & 41.67 & 95 & 79.17 & \multirow[t]{4}{*}{0.00} \\
\hline Twice a week & 26 & 21.67 & 12 & 10.00 & \\
\hline Once a week & 21 & 17.50 & 9 & 7.50 & \\
\hline Others (less than once A week) & 5 & 4.17 & 4 & 3.33 & \\
\hline
\end{tabular}




\begin{tabular}{|c|c|c|c|c|c|}
\hline \multirow{3}{*}{ Items } & \multicolumn{4}{|c|}{ Study group $(n=120)$} & \multirow{3}{*}{ P-value } \\
\hline & \multicolumn{2}{|c|}{ Pre-intervention } & \multicolumn{2}{|c|}{ Post-intervention } & \\
\hline & No. & $\%$ & No. & $\%$ & \\
\hline \multicolumn{6}{|l|}{ Consumed Product } \\
\hline Milk & 80 & 66.67 & 119 & 99.17 & \multirow{3}{*}{0.0026} \\
\hline Yogurt & 38 & 31.67 & 105 & 87.50 & \\
\hline Cheese its types & 60 & 50.00 & 99 & 82.50 & \\
\hline \multicolumn{6}{|l|}{ Symptoms of calcium deficiency } \\
\hline None & 12 & 10.00 & 2 & 1.67 & \multirow{8}{*}{$0.71 \mathrm{~ns}$} \\
\hline Insomnia & 15 & 12.50 & 2 & 1.67 & \\
\hline Nervousness, irritability and mood swing & 52 & 43.33 & 10 & 8.33 & \\
\hline Feeling of numbness in arms \& legs & 20 & 16.67 & 8 & 6.67 & \\
\hline Decrease muscle power & 24 & 45.00 & 4 & 3.33 & \\
\hline Problem in teeth (drop or decay) & 50 & 41.67 & 15 & 12.50 & \\
\hline Pain or inflammation in joint and legs & 24 & 20.00 & 6 & 5.00 & \\
\hline Vertigo or palpitation & 42 & 35.00 & 14 & 11.67 & \\
\hline
\end{tabular}

Table (5): Distribution of complications of pregnancy during breastfeeding after the educational program

\begin{tabular}{|c|c|c|c|c|c|}
\hline \multirow{3}{*}{ Complication during current pregnancy } & \multicolumn{2}{|c|}{ Study group $(\mathrm{n}=120)$} & \multicolumn{2}{|c|}{ Control group $(\mathbf{n}=120)$} & \multirow{2}{*}{ P-value } \\
\hline & No. & $\%$ & No. & $\%$ & \\
\hline & 66 & 55.0 & 94 & 78.3 & $0.001 . * *$ \\
\hline Miscarriage & 1 & 0.8 & 3 & 2.5 & $0.01 *$ \\
\hline \multicolumn{5}{|l|}{ Time of miscarriage } & \multirow{4}{*}{$0.05 *$} \\
\hline $1^{\text {st }}-3^{\text {rd }}$ month & 0 & 0.0 & 2 & 1.7 & \\
\hline $4^{\text {th }}-6^{\text {th }}$ month & 1 & 0.8 & 1 & 0.8 & \\
\hline $7^{\text {th }}-9^{\text {th }}$ month & 0 & 0.0 & 0 & 0.0 & \\
\hline Vaginal bleeding during pregnancy & 3 & 2.5 & 5 & 4.2 & $0.04 *$ \\
\hline Placental separation (partially or completely) & 3 & 2.5 & 5 & 4.2 & $0.04^{*}$ \\
\hline Delayed fetal growth & 7 & 5.8 & 10 & 8.3 & $0.05^{*}$ \\
\hline Elevation of blood sugar & 5 & 4.2 & 8 & 6.7 & $0.05^{*}$ \\
\hline Elevation of blood pressure & 20 & 16.7 & 17 & 14.2 & 0.06 \\
\hline Eclampsia & 5 & 4.2 & 9 & 7.5 & $0.05^{*}$ \\
\hline Anemia & 21 & 17.5 & 34 & 28.3 & $0.04 *$ \\
\hline
\end{tabular}

Table (6) :Distribution of variables related to labor and complication in the two groups after the educational program

\begin{tabular}{|c|c|c|c|c|c|}
\hline & \multicolumn{2}{|c|}{ Study group $(n=120)$} & \multicolumn{2}{|c|}{ Control group $(\mathrm{n}=120)$} & \\
\hline & No. & $\%$ & No. & $\%$ & \\
\hline \multicolumn{5}{|l|}{ Time of delivery } & \multirow{4}{*}{0.03} \\
\hline At 37 weeks & 90 & 75.00 & 80 & 66.7 & \\
\hline 37 weeks)>) Preterm labor & 16 & 13.3 & 25 & 20.8 & \\
\hline 40 weeks)< ) Post date & 14 & 11.7 & 15 & 12.5 & \\
\hline \multicolumn{5}{|l|}{ Mode of delivery } & \multirow{3}{*}{0.02} \\
\hline Normal & 79 & 65.8 & 69 & 57.5 & \\
\hline $\mathrm{CS}$ & 41 & 34.3 & 51 & 42.5 & \\
\hline
\end{tabular}




\begin{tabular}{|c|c|c|c|c|c|}
\hline & \multicolumn{2}{|c|}{ Study group $(n=120)$} & \multicolumn{2}{|c|}{ Control group $(n=120)$} & \\
\hline & No. & $\%$ & No. & $\%$ & \\
\hline \multicolumn{6}{|l|}{ Complications of normal delivery } \\
\hline Ante-partum hemorrhage & 2 & 1.7 & 5 & 2.4 & 0.01 \\
\hline Post-partum hemorrhage & 4 & 3.3 & 7 & 5.8 & 0.01 \\
\hline Premature rupture of membranes & 17 & 14.2 & 15 & 12.5 & 0.01 \\
\hline Prolonged labor & 18 & 15.00 & 15 & 12.5 & 0.04 \\
\hline None & 38 & 31.7 & 27 & 22.5 & 0.010 \\
\hline \multicolumn{6}{|l|}{ Indication of CS } \\
\hline Contracted pelvis & 11 & 9.2 & 14 & 11.7 & $* 0.05$ \\
\hline Macrocosmic baby & 3 & 2.5 & 18 & 15.00 & $* * 0.001$ \\
\hline Abnormal position of fetus & 11 & 9.2 & 16 & 13.3 & 0.04 \\
\hline Prolonged labor & 10 & 8.3 & 9 & 7.5 & 0.06 \\
\hline Ante-partum hemorrhage & 2 & 1.7 & 4 & 3.3 & 0.02 \\
\hline
\end{tabular}

Table (7): Distribution of newborn data in the two-studied groups

\begin{tabular}{|c|c|c|c|c|c|}
\hline \multirow{2}{*}{ Items } & \multicolumn{2}{|c|}{ Study group $(n=120)$} & \multicolumn{2}{|c|}{ Control group $(n=120)$} & \multirow{2}{*}{ P-value } \\
\hline & No. & $\%$ & No. & $\%$ & \\
\hline \multicolumn{5}{|l|}{ Condition of the baby } & \multirow[b]{2}{*}{0.123} \\
\hline Live birth & 119 & 99.17 & 117 & 97.5 & \\
\hline \multicolumn{5}{|l|}{ Birth weight } & \multirow{3}{*}{0.085} \\
\hline Mean \pm SD & \multirow{2}{*}{\multicolumn{2}{|c|}{$3022.01 \pm 315.6$}} & \multicolumn{2}{|c|}{$2951.3 \pm 312.5$} & \\
\hline Range & $4200-2000 \mathrm{mg}$ & & \multicolumn{2}{|c|}{$4100-2000 \mathrm{mg}$} & \\
\hline \multicolumn{5}{|l|}{ Birth weight } & \multirow{3}{*}{0.087} \\
\hline Normal & 109 & 91.6 & 99 & 84.6 & \\
\hline$<2500 \mathrm{gm}$ & 10 & 8.4 & 18 & 15.4 & \\
\hline \multicolumn{5}{|c|}{ Time of starting breast feeding after delivery } & \multirow{4}{*}{0.91} \\
\hline Within 1 hour & 42 & 35.00 & 40 & 33.4 & \\
\hline Within 6 hours & 63 & 52.5 & 67 & 55.8 & \\
\hline More than 6 hours & 15 & 12.5 & 13 & 10.8 & \\
\hline Referred to PCU & 50 & 41.7 & 58 & 48.4 & 0.08 \\
\hline \multicolumn{6}{|l|}{ Cause of referral } \\
\hline Convulsion & 1 & 0.8 & 1 & 0.8 & $\overline{--}$ \\
\hline Respiratory distress & 10 & 8.4 & 12 & 10.00 & 0.123 \\
\hline Small for gestational age & $\mathbf{1 0}$ & 8.4 & 11 & 9.2 & 0.213 \\
\hline Less than 2500 gm. & 11 & 9.2 & 12 & 10.00 & 0.214 \\
\hline Jaundice & 18 & 15.00 & 22 & 18.4 & 0.080 \\
\hline
\end{tabular}

Table (1) : showed that the mean age of the studied women were $28.82 \pm 4.22$ years in the study group and $29.33 \pm 5.20$ in the control with no statistical significant difference. Regarding husband occupation, level of education and mother's occupation, there was no statistical significant difference.

The past obstetric history of the studied women is presented in table (2): Almost more than half of the control $61.5 \%$, and about three fourth of the PDBF2 group $84.4 \%$ had more than one previous delivery with highly statistically significant difference. The mean number of previous deliveries in the control group was $2.39 \pm 1.54$ and in the study group was $2.64 \pm 1.18$. Concerning history of previous miscarriages, the majority of women in both groups (77.8\% in the control group and $85.6 \%$ in the study group) had no previous miscarriages, with no statistically significant difference $(\mathrm{P}=0.100)$. Likewise, $14.4 \%$ of the control group and $16.3 \%$ of the study group reported previous pregnancy while breastfeeding. In addition, $78.5 \%$ of the control group and $77.7 \%$ of study group had unintended pregnancies. Also, $71 \%$ and $70 \%$ of control group, study group didn't use contraceptives. 
Breastfeeding history is illustrated in the table (3) : The table showed that all studied women breastfed their children. The mean duration of breastfeeding was $17.76 \pm 5.24$ and $21.22 \pm 3.16$ months respectively. The mean age of youngest child at the time of recruitment in the study was $13.02 \pm 4.60$ and $14.04 \pm 4.55$ months for control and study groups respectively. Also, the mean duration of breastfeeding while pregnant at the current pregnancy till delivery, was $12.25 \pm 4.71$ and 19.17 \pm 3.99 months for the control and study groups respectively.

Table (4) : clarified comparison between knowledge of women in the study group regarding component of balanced meal. The table showed that there was highly statistical significant improvement in women's correct knowledge and consumption of milk product after the educational program than that of the control group.

Table (5) illustrated the distribution of complications of pregnancy during breastfeeding after the educational program. The table showed statistical significant decrease among the study group than that of the control groups regarding complications as miscarriage, vaginal bleeding during pregnancy, placental separation, delayed fetal growth, elevation of blood sugar, eclampsia and anemia. However, no statistical significant difference was found between the study group and control group in relation to elevation in blood pressure.

Table (6) : showed distribution of variables related to labor and complication in the two groups. The table clarified that the time of delivery, mode of delivery, complication of delivery, and indication for $\mathrm{CS}$, were better among the study group than that of the control group. Also, the percentage of women who had cesarean section was higher $(42.5 \%)$ in the control group, compared to $34.2 \%$ women in the study group. However, only less than one third of women in both groups reported no complications during normal delivery. Table (7) : clarified no statistical significant differences between the two groups in relation to condition of baby, weight, referral to PCU and time for initiation of breastfeeding. However, $91.6 \%$ of babies for the study group have normal weight compared to $84.6 \%$ in the control group. Also, $41.7 \%$ of newborns' of the study group were referred to PCU compared to $48.4 \%$ of the control group.

\section{Discussion}

Breastfeeding for long periods is common practice among Egyptians women who are having a high total fertility rate and almost inadequate dietary intake and short inter -pregnancy interval that should necessary need an appropriate interval between breastfeeding and the next pregnancy (WHO, 2004, Speroff and Mishell, 2008). Therefore, it is of great health importance to know the effects of pregnancy during lactation on pregnancy outcome.

The result of present study revealed that the mean age of women who were pregnant during breastfeeding in both groups, the findings illustrated that they were middle age between $28.82 \pm 4.22$ years in the study group and $29.33 \pm 5.20$ in the control group who, with no statistical significant differences (table 1): This finding was congruent with Sengul et al., (2012) who conducted a study in Turkey to assess the outcomes of the pregnancies of lactating women and reported that women in both groups were middle age with no significant difference between the ages of two groups. At the same line this results were supported by Tilley et al., (2009) and Albadran, (2013) who conducted a study to explore whether breastfeeding during pregnancy increases the risk of miscarriage and preterm births reported that there they were middle age with no significant difference between the ages of the two groups.

Concerning mother's education the current study showed that less than half of the subjects in both groups have basic education with no significant difference between both groups. This result was supported by Marquis et al., (2002) who conducted a study to determine the effect of an overlap of lactation and late pregnancy on breastfeeding and growth in early infancy and found that breastfeeding -pregnancy and non-breastfeeding -pregnancy mothers had similar level of education.

Regarding pregnancy intention, it was estimated that the majority of pregnancies in both groups were unintended and about $70 \%$ of them did not use contraceptive methods with no statistical significant difference between the two group (table 2). These results agreed with Huang et al., (2012) who reported that $86 \%$ of unintended postpartum pregnancies occurred without contraceptive usage and $88 \%$ of them resulted in induced abortion. In addition, this finding was in the same line with Shaaban, (2008) who conducted a study in Assiut, Egypt, to describe the prevalence of pregnancy during breastfeeding, contraceptive practice and unintended pregnancy among women in rural Egypt and illustrated that unintended pregnancy is common among breastfeeding women. This finding could be due to lack of knowledge about complications of PDBF and lack of proper counseling about contraceptive use or when to use it.

The mean age of youngest child at the time of delivery was $13.02 \pm 4.60$ and $14.04 \pm 4.55$ months for control and study groups respectively. Also, the 
mean duration of breastfeeding while pregnant at the current pregnancy till delivery, was $12.25 \pm 4.71$ and $19.17 \pm 3.99$ months for the control and study groups respectively. Birth spacing is an important element of making pregnancy safer, so WHO, (2005), and UNICEF (2006, 2009) recommend that women breastfeed each child for at least 2 years for the benefit of its nutritional status, growth and development, and general health and to reduce the incidence of maternal and fetal risks in each pregnancy but not while pregnant. This could be due to lack of antenatal care and lack of proper information about needs of the child to be breastfed and nutritional needs of the mother and the new comer.

Concerning Calcium intake, the results of the present study showed that the majority of women in the study group knew the symptoms of low calcium intake than those of the control group. Also, their consumption of milk and milk products is better than that of the control group. This improvement may support the study hypothesis which predicts that pregnant -lactating women who will receive the educational intervention will have better outcomes than those in the control group.

Table (7) : clarified no statistical significant differences between the two groups in relation to condition of baby, weight, referral to PCU and time for initiation of breastfeeding. However, 91.6\% of babies for the study group have normal weight compared to $84.6 \%$ in the control group. Also, $41.7 \%$ of newborns' of the study group were referred to PCU compared to $10 \%$ of the control group.

The results of the present study showed that there was statistical significant difference between pregnancy-breastfeeding overlap and complication during current pregnancy. However, the percentage was high in both groups since almost only one third of both groups didn't have any complications. This result contradicts Madarshahian et al., (2012) who conducted a study to compare the rates of success in reaching full-term delivery and newborn birth weight between two groups of women, those who get pregnant while breastfeeding and those who did not, and found no statistical significant difference in the occurrence of problems during pregnancy between the two groups. Also, Sengul et al., (2012) who found no statistical significant differences in obstetric complications occurrence in the pregnancies of lactating women. The contradiction with the current findings may be due to type of antenatal care rendered to women in addition to nutritional burden on the woman, especially with the well-known inadequate dietary intake among women in Upper Egypt which in turn affect the fetal growth. Regarding anemia, the result of the present study revealed that there was statistical significant difference $\quad(\mathrm{P}=0.005) \quad$ between pregnancybreastfeeding overlap and incidence of anemia This finding was supported by Dairo and Lawoyin (2004) who found an association between interpregnancy intervals shorter than 24 months and increased risk of anemia during pregnancy. This finding might be because short intervals could indirectly increase the risk of adverse effect of nutritional needs of the pregnant lactating women.

According to the findings of the current study, there is statistical significant increase in the percentage of CS among the control group than that of the study group $(\mathrm{p}=0.001)$. These results agreed with Berkowitz et al., (2008) who conducted a study about the risk factor for preterm birth and found that mothers in the control group has a significant increase risk for CS. Also Lucke and Brow, (2007) who conducted a study of the risk of maternal morbidity and adverse outcomes showed that increasing maternal nutritional needs was associated with higher risk of CS. It may be because women in the study group benefited from theeducationa lprogram and improved their nutritional intake, periods of sleep and rest and hygienic practices. However, the percentage of CS was high in the two groups.

As for the effect of the educational program on the infant, the findings indicated that there were no statistical significant differences between newborns of the two groups. However, less than half of the newborn in the study group were referred to the PCU compared to almost half of the control group. In addition the percentage of Macrocosmic baby was higher among the newborn of the control group than that of the study group. These findings were congruent with Sengul et al., (2012) who reported that the risk of depletion of nutrient stores in the breastfeeding pregnant mother lead to growth retardation of the fetus and might increase, particularly among malnourished women. Likewise, Conde-Agudelo et al., (2012) clarified that short intervals could indirectly increase the risk of adverse neonatal/infant outcomes through changes in breastfeeding patterns or the composition and/or quantity of breast milk secondary to breastfeedingpregnancy overlap. This finding could be because PDBF women whose nutritional status was poor when they conceived or who didn't gain enough weight during pregnancy may deliver babies with low birth weight. Finally this findings support the second hypothesis and Infants of PDBF women who received the educational program had improved outcomes than those in the control group. 


\section{Conclusions}

Pregnant -lactating women who received the educational program have improved outcomes than those in the control group although there were no statistical significant differences in some of the variables.

Infants of PDBF women who received the educational program had improve outcomes than those in the control group although there were no statistical significant differences in some of the variables.

\section{Recommendation}

Recommendation Based on the results of the present study, the researcher suggested the following recommendations

- Continuous postnatal counseling and health education classes about:

- Nutritional needs focusing on pregnancy to prevent complication for mothers and their children during breast feeding and weaning practices.

- Different methods of family planning to avoid unintended pregnancies.

- prevent complications for mothers and their children.

\section{References}

1. Berkowitz, G., Blackmore-prince C., Lapinski, R., and Savitz D., (2008): Risk factors for preterm birth .Epidemiology; 9: Pp279-285.

2. Brown L., (2010): Nutritional Requirements during pregnancy 15(2) Pp 16-18.

3. Centers for Disease Control and Prevention(CDC), (2005): Use of dietary supplements containing folic acid among women of childbearing age United States, MMWR, 54(38), Pp955-58.

4. Conde-Agudelo A., Rosas-Bermudez A., Castaño F., \& Maureen H., (2012): Effects of Birth Spacing on Maternal, Prenatal, Infant, and Child Health: A Systematic Review of Causal Mechanisms 43 (2): Pp 100-102.

5. Dairo, Magbagbeola, D., \& Taiwo O., Lawoyin, F., (2004): "Socio-demo-graphic determinants of anemia in pregnancy at primary care level: A study in urban and rural Oyo State, Nigeria," African Journal of Medicine and Medical Sciences; 33(3): Pp213-217.

6. Fathalla M., Abdel-Raheem M., \& Amin A., (2003): The prevalence, determinants and outcome of unintended pregnancy: a hospital- based study. J., EgyptSocObstetGynecol; 29: PP945-54.

7. Goma S., (2011): emergency contraception as a back up of lactation amenorrhea method of contraception, pp20-21.

8. Grimes D., Benson J., Singh S., Romero M., Ganatra B., andOkonofua F., (2006): Unsafe abortion: the preventable pandemic. Lancet, 368:Pp1908-19.

9. Houghton L.,(2009) : Nutrition and supplement during pregnancy .Department of human nutrition, University of Otage

http://www.moh.govt.nz

10. Huang Y., Merkatz R., Kang J., Roberts K., and D., Donato F., (2012): Postpartum unintended pregnancy and contraception practice among rural-to-urban migrant women in Shanghai. Contraception; 86: Pp731-8.

11. Ismail S., Abd-Ellah M., \& Abd El-Khair A., (2009): Study of Probable Effects of a New Pregnancy on Some Milk Constituents in Lactating Women Research Journal of Medicine and Medical Sciences; 4(1): Pp49-54.

12. Lakha F., Glasier A., (2006): Unintended pregnancy and use of emergency contraception among a large cohort of women attending Shah I., Ahman E., (2009): Unsafe abortion: global and regional incidence, trends, consequences, and challenges. J Obstet Gynecology Can, 31:1149-58.

13. Lucke B., and Brown M., (2007): Risk of maternal morbidity and adverse outcomes with increase maternal age and plurality. Fertile .steril; 88(2):Pp283-293.

14. Madarshahian F., and Hassanabadi M., (2012 :(A comparative study of breastfeeding during pregnancy: impact on maternal and newborn outcomes. J Nurs Res.; 20 (1 :(Pp-74 .80

15. Marquis G., Penny M., Diaz J., Judith M., Diaz and R., Marín M., (2002): Postpartum Consequences of an Overlap of Breastfeeding and Pregnancy Reduced Breast Milk Intake and Growth during Early Infancy, PEDIATRICS Vol. 109 No .4.Pp1-8.

16. Maysara M., \& Albadran, M., (2013): Effect of Breastfeeding during Pregnancy on the Occurrence of Miscarriage and Preterm Labour. Iraqi Journal of Medical Sciences; Vol. 11(3):Pp285-89.

17. Ministry of health, (2006):food and nutrition guidelines for healthy, pregnant and breastfeeding women; pp2-3

18. Pareja R., (2007): The association between breastfeeding during late pregnancy and the occurrence of small for gestational age and 
prolonged active phase of labor among Peruvian women 21(4) :Pp1-14.

19. Sengul O., Sivaslioglui A., Kokanali M., \& Ustuner I., (2012): The outcomes of the pregnancies of lactating women, Turkish Journal of Medical Sciences 43: Pp251-254.

20. Shaaban O., \& Glasier A., (2008): Pregnancy during breastfeeding in rural Egypt. Contraception, 77:Pp350-354

21. Smith G., Pell J., \& Dobbie R., (2003): Interpregnancy interval and risk of preterm birth and neonatal death: retrospective cohort

22. Speroff L., \& Mishell D., (2008): The postpartum visit: it's time for a change in order to optimally initiate contraception. Contraception, 78: Pp8-90

23. Tilley B., Shaaban M., Wilson M., Glasier A., Daniel R., \& Mishell J., (2009): Breastfeeding and contraception use among women with unplanned pregnancies less Than 2 years after delivery. International Journal of Gynecology and Obstetrics International Journal of Gynecology and Obstetrics 105: Pp127-130.

24. UNICEF, 2006: Celebrations the Innocent Declaration on the protection promotion and support of breastfeeding $.2^{\text {nd }}$ Ed .Florence; Pp115

25. UNICEF, 2009 : Tracking Progress on Child and Maternal Nutrition, UNICEF Launches New Report on Child and Maternal Nutrition pp1-3

26. World Health Organization, (2005): Department of Making Pregnancy Safer and Department of Reproductive Health and Research. Report of a WHO Technical Consultation on Birth Spacing. Geneva. 